\title{
Desempenho Acadêmico e o Ingresso no Curso Superior: uma análise das estudantes ingressantes entre 2016 a 2020 do curso Técnico em Informática Integrado ao Ensino Médio
}

\author{
Daniela Marques ${ }^{1}$, André Constantino da Silva ${ }^{1}$, Gustavo Bartz Guedes ${ }^{1}$, Carlos \\ Roberto dos Santos Junior ${ }^{1}$ \\ ${ }^{1}$ Instituto Federal de São Paulo (IFSP) \\ Hortolândia - SP - Brazil \\ \{marquesdaniela, andre.constantino, gubartz, \\ carlos.rsantos\} @ifsp.edu.br
}

\begin{abstract}
Papers show that the participation of the female public in higher education courses and in the corporate world in the computer area has been decreasing over time. However, in the technical course in Computer Science area integrated with high school at the Federal Institute of São Paulo, Hortolândia campus, the majority of female students was noted, which motivated this research. This paper analyzes students' grades in technical aspects in relation to the common core subjects available in high school since most female students said they were not interested in the course or in the course area and evaluate the difference in performance between the subjects and the chosen area for college.
\end{abstract}

Resumo. Artigos mostram que a participação do público feminino nos cursos superiores e no mercado coorporativo na área de Computação vem diminuindo com o passar do tempo. Porém, no curso Técnico em Informática Integrado ao Ensino Médio do Instituto Federal de São Paulo, campus Hortolândia, notouse maioria de estudantes do sexo feminino, o que motivou esta pesquisa. Este artigo faz uma análise das notas das alunas nas disciplinas práticas em relação ao núcleo de formação geral uma vez que a maioria das alunas disseram não ter interesse no curso ou na área do curso e avalia a diferença de desempenho entre as disciplinas e a área escolhida para o curso superior.

\section{Introdução}

Muitas são as iniciativas para estimular a participação das mulheres na carreira de exatas, tais como comunidades como PyLadies [Pyladies 2021] e Women Who Code [Women 2021]. A Sociedade Brasileira de Computação (SBC) criou o Programa Meninas Digitais cujo objetivo é divulgar a área da Computação e tecnologias às estudantes do Ensino Médio para que sejam motivadas a estudar nesta área [Meninas 2021]. Empresas também apoiam a participação das mulheres através de seus programas, no intuito de discutir os problemas enfrentados pelas trabalhadoras [ISACA 2017].

Dentro do mundo universitário, considerando o senso da Educação Superior com dados coletados em 2019 [INEP 2019], a maioria dos estudantes concluintes do curso superior são do sexo feminino, porém em cursos de Computação e Tecnologias da Informação e Comunicação (TIC), estudantes do sexo feminino representam somente $13,6 \%$. 
O Instituto Federal de São Paulo (IFSP), oferece cursos técnicos na modalidade Integrado ao Ensino Médio, Concomitante/Subsequente e cursos de graduação (tecnólogo, bacharel e licenciatura) na área de exatas. Especificamente em relação ao Curso Técnico em Informática Integrado ao Ensino Médio, houve aumento crescente de estudantes do sexo feminino ao longo dos anos de 2016 a 2020 [Marques e Silva 2019] e, desde 2017, são maioria entre os alunos ingressantes.

Curso Técnicos Integrados ao Ensino Médio é uma modalidade de ensino na qual o estudante é conduzido à habilitação profissional técnica de nível médio na mesma instituição de ensino que recebe a formação básica do Ensino Médio [Brasil 2004]. Aqui utilizaremos o termo propedêutica para referenciar as disciplinas de formação básica e disciplinas técnicas para as disciplinas profissionalizantes.

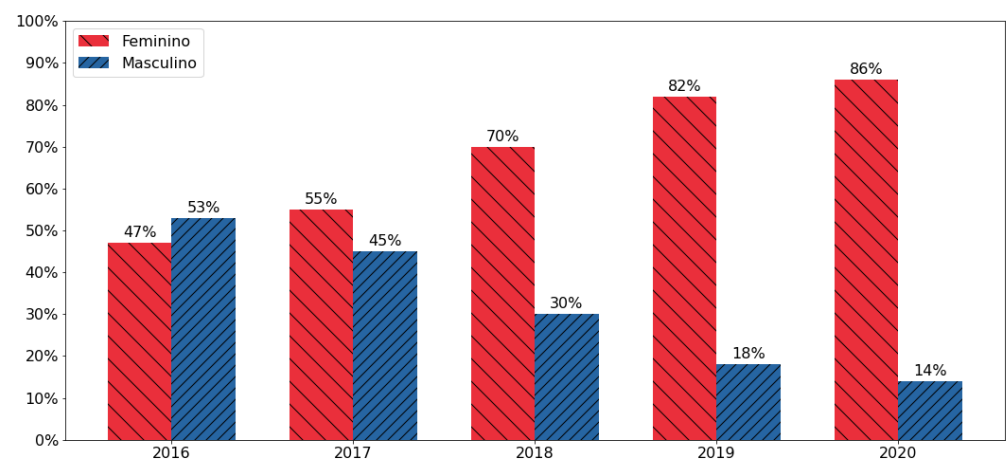

\section{Figura 1. Porcentagem de estudantes no curso Técnico em Informática Integrado ao Ensino Médio por ano de ingresso e sexo}

Observando esse crescente aumento de estudantes do sexo feminino, o trabalho de Marques e Silva (2019) apresenta um estudo sobre as possíveis razões que motivam as estudantes em sua escolha por este curso técnico integrado e concluíram que a afinidade ou interesse com a Informática ou área de exatas não é o fator principal para a escolha, mas sim a inexistência do curso desejado na unidade ou nas proximidades. Diferentemente, os estudantes do sexo masculino escolheram pela identificação com o curso. Essa constatação pode ter diversas consequências, dentre as quais podemos refletir: (i) se as estudantes teriam baixo desempenho nas disciplinas técnicas uma vez que a área técnica escolhida não é o principal fator de escolha do curso e (ii) se o fato de realizar o curso técnico poderia mudar a opinião das estudantes para continuar a formação na área da Computação ou seguir uma carreira na área.

Este trabalho leva em consideração as notas das estudantes que participaram da pesquisa a qual afirmaram que o interesse pelo curso foi por motivo excludente, porém, em termos de pesquisa, gostaríamos de saber se essa decisão influenciaria nas notas no decorrer do curso. Para isso foram propostas as seguintes hipóteses:

- H1) As estudantes ingressam no curso Técnico Integrado escolhido, e, devido à falta de interesse na área técnica do curso, tiram notas menores nas disciplinas técnicas se comparadas as disciplinas do propedêutico.

- H2) As estudantes que ingressaram no Ensino Superior estão cursando graduações nas áreas de conhecimento na qual elas tiveram as maiores notas durante o curso Técnico Integrado. 
- H3) Existe relação entre as disciplinas que as estudantes tiveram as maiores notas durante o curso e a escolha da área para ingresso no Ensino Superior.

Este artigo tem como objetivo responder essas questões continuando a pesquisa feita por Marques e Silva (2019) cujo objetivo é compreender o interesse das estudantes dentro do nosso campus. Essas pesquisas servem como insumo para melhoria do curso assim como tomada de ações para despertar o interesse das estudantes na área de Ciências Exatas.

O artigo está dividido da seguinte maneira: a Seção 2 apresenta a metodologia adotada no trabalho; a Seção 3 mostra a análise dos dados e uma breve discussão e, por último, a Seção 4 conclui a pesquisa feita.

\section{Metodologia}

Conforme citado, o curso Técnico em Informática Integrado ao Ensino Médio do IFSP, campus Hortolândia, tem em sua maioria estudantes do sexo feminino, essa tendência vem ocorrendo desde a abertura do curso (Figura 1). No entanto, mesmo com uma grande procura, as estudantes afirmaram não ter interesse na área de exatas 0 .

Visando compreender o interesse das estudantes no curso, queremos entender se a falta de interesse pela área técnica no momento do ingresso da estudante implica em menos dedicação ou notas inferiores nas disciplinas que conduzem à habilitação técnica (hipótese H1).

Devido a hipótese estar relacionada diretamente ao desempenho acadêmico das estudantes, analisou-se os registros existentes dos diários escolares. A primeira etapa foi a extração dos dados de interesse dos diários, removendo os dados sensíveis que poderiam identificar um estudante. A partir dos dados foram gerados gráficos para análise e compreensão do rendimento dos estudantes nas disciplinas, considerando gênero feminino e masculino.

Uma vez analisadas as notas de todos os estudantes, foi aplicada uma pesquisa com os alunos egressos para identificar a opinião deles em relação ao curso e disciplinas. O Quadro 1 apresenta as questões aplicadas a todos os alunos egressos. Antes de possibilitar ao voluntário responder às questões, o formulário apresentava o Termo de Consentimento Livre e Esclarecido (TCLE).

Quadro 1. Questionário aplicado aos estudantes egressos

\begin{tabular}{|l|}
\hline Perguntas \\
\hline Qual o curso técnico INTEGRADO que você estudou? \\
\hline Qual o seu sexo? \\
\hline $\begin{array}{l}\text { Notamos que as notas do Ensino Médio das disciplinas técnicas foram tão boas como das áreas do } \\
\text { propedêutico (biologia, sociologia, química, etc.). Selecione o principal motivo de você se esforçar em } \\
\text { tirar boas notas na parte técnica: }\end{array}$ \\
\hline Você seguiu seus estudos (mais cursos ou uma faculdade) após o curso técnico? \\
\hline Se você continuou seus estudos, qual a área que você está cursando atualmente? \\
\hline Está fazendo faculdade? Qual o curso e qual faculdade? \\
\hline Realizar o curso técnico ajudou você: \\
\hline
\end{tabular}




\section{Análise dos dados e discussão}

Para responder a primeira hipótese, foram extraídos dados dos diários entregues do período de 2016 a 2019. Até 2019, cada um dos três anos do ciclo de formação Ensino Médio possui 16 disciplinas, portanto 16 diários. Considerando que nosso curso foi aberto em 2016, nesse ano somente havia turma para o $1^{\circ}$ ano do ciclo, portanto 16 diários. Em 2017, devido a progressão da turma e o ingresso de novos estudantes, haviam uma turma para o $1^{\circ}$ ano e uma turma para o $2^{\circ}$ ano, totalizando 32 diários neste ano. Em 2018, devido a se ter os três anos do ciclo de formação, foram lançados 48 diários para cada ano civil. Em 2019, o projeto de curso passou por uma reformulação e com isso, os alunos ingressantes passaram a ter 15 disciplinas, portanto 15 diários, e os outros anos somaram 32 diários no total. Assim, totalizam-se 143 diários utilizados na extração de dados. O ano de 2020 não foi incluído na pesquisa pois, em função da pandemia, o ano letivo não foi encerrado na instituição até o término deste trabalho. Para a análise dos dados foram removidas as linhas que não continham informação no campo nota, que pode ocorrer devido a transferência de escola por parte do aluno. São oferecidas 40 vagas para cada abertura de nova turma.

Conforme apresentado na Figura 2, em relação ao desempenho acadêmico no ano, a média geral das notas das estudantes se mostra um pouco maior às dos estudantes.

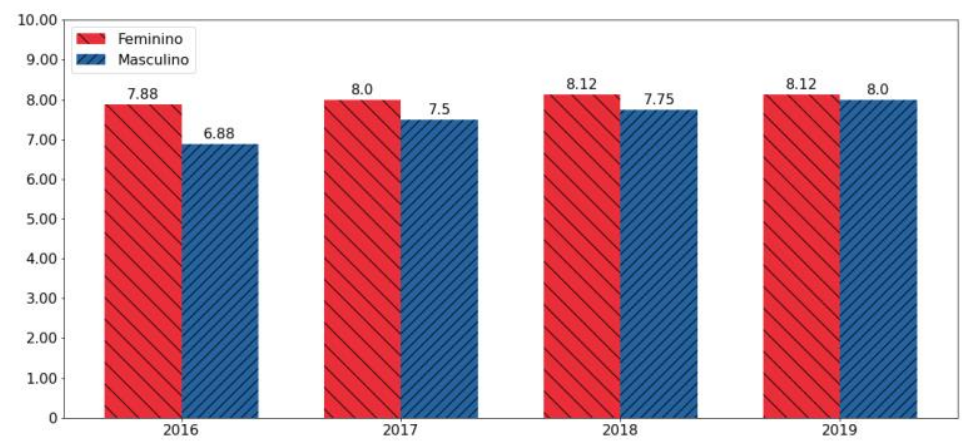

Figura 2. Média geral por ano de ingresso e sexo

Após análise das médias das disciplinas por ano de estudo, $1^{\circ}, 2^{\circ}$ ou $3^{\circ}$ ano do Ensino Médio, notou-se que há um bom desempenho das estudantes nas disciplinas, mesmo que a maioria das estudantes não tenha optado por realizar o curso por interesse na área de Computação. A Figura 3 apresenta as médias obtidas pelos estudantes nos 3 períodos do Ensino Médio.

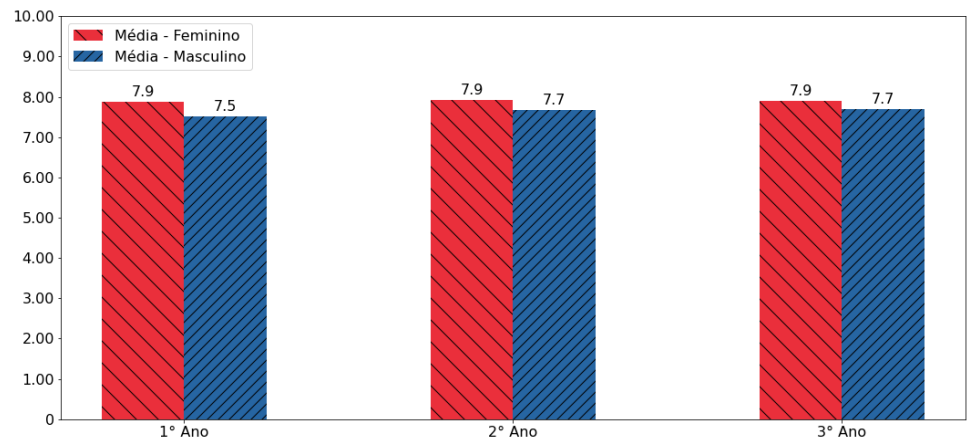

Figura 3. Média geral dos estudantes nos três anos do curso Técnico Integrado ao Ensino Médio em Informática 
Outro fator importante observado é que as estudantes, no geral, têm um maior desempenho nas médias das disciplinas (Figura 4). Considerando os alunos ingressantes de 2016, representada como a Turma 1 (T1 na Figura 4), somente no terceiro ano que os estudantes tiveram uma média maior do que as estudantes. Em 2017, Turma 2 (T2), as estudantes obtiveram uma média maior durante todo os anos do curso. Os ingressantes de 2018, Turma 3 (T3), a média das notas das estudantes foi superior no primeiro ano do curso e, no segundo ano, ficou 0,2 pontos abaixo da média dos estudantes.
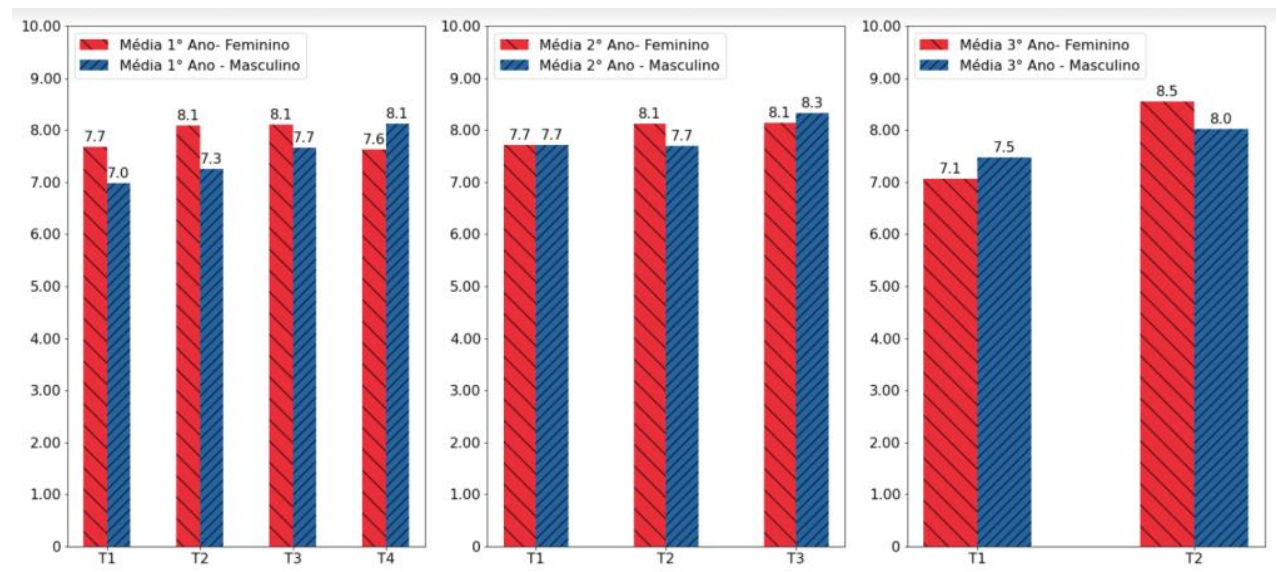

Figura 4. Média geral nos três anos do curso Técnico Integrado ao Ensino Médio por sexo

A Figura 5 apresenta as médias das notas das estudantes obtidas nas disciplinas técnicas e propedêuticas conforme a turma e o ano do curso (primeiro, segundo ou terceiro). Pelo gráfico é possível observar que a média obtida pelas estudantes são superiores à média exigidas pela Instituição para aprovação, ou seja, 6,0 (seis). Observase também que o desempenho nas disciplinas técnicas é, algumas vezes, superior à média obtida em disciplinas que compõem a parte propedêutica, principalmente no ano de ingresso do curso.

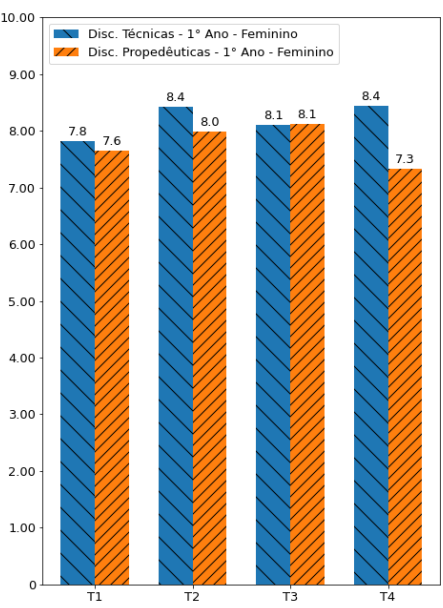

(a)

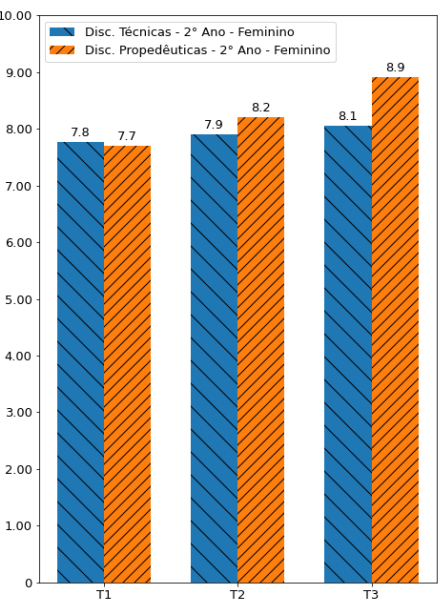

(b)

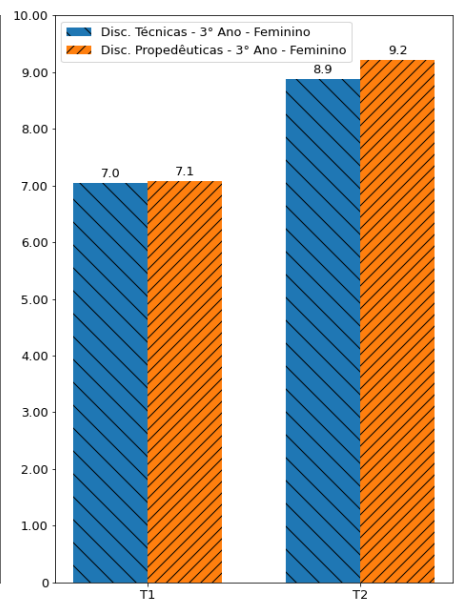

(c)

Figura 5. Média geral das disciplinas técnicas e propedêuticas agrupadas entre o (a) primeiro, (b) segundo ou (c) terceiro ano do curso

Ao contrário das turmas do primeiro ano do Ensino Médio (Figura 5a), as estudantes no segundo ano (Figura $5 \mathrm{~b}$ ) têm um maior desempenho em disciplinas da parte 
propedêutica. No terceiro ano do curso (Figura 5c), a maioria das estudantes mantêm um melhor desempenho em disciplinas do propedêutico e na disciplina técnica de Projeto Integrador.

Para verificar a hipótese 2 (H2), o questionário apresentado no Quadro 1 foi disponibilizado no portal institucional do campus e na rede social, tanto no perfil institucional como no perfil do grêmio estudantil. Foram obtidas 34 respostas, o que representa $56 \%$ dos alunos formados. Considerando o público feminino, obtivemos $65 \%$ do total dos formados.

Em relação a questão sobre os motivos das "notas do Ensino Médio das disciplinas técnicas foram tão boas como das áreas do propedêutico", 67\% das estudantes responderam que se preocupavam com o histórico final, $14 \%$ que tinham facilidade com o conteúdo, seguidas por outras alternativas. A Figura 6 exibe as respostas obtidas pelo questionário.

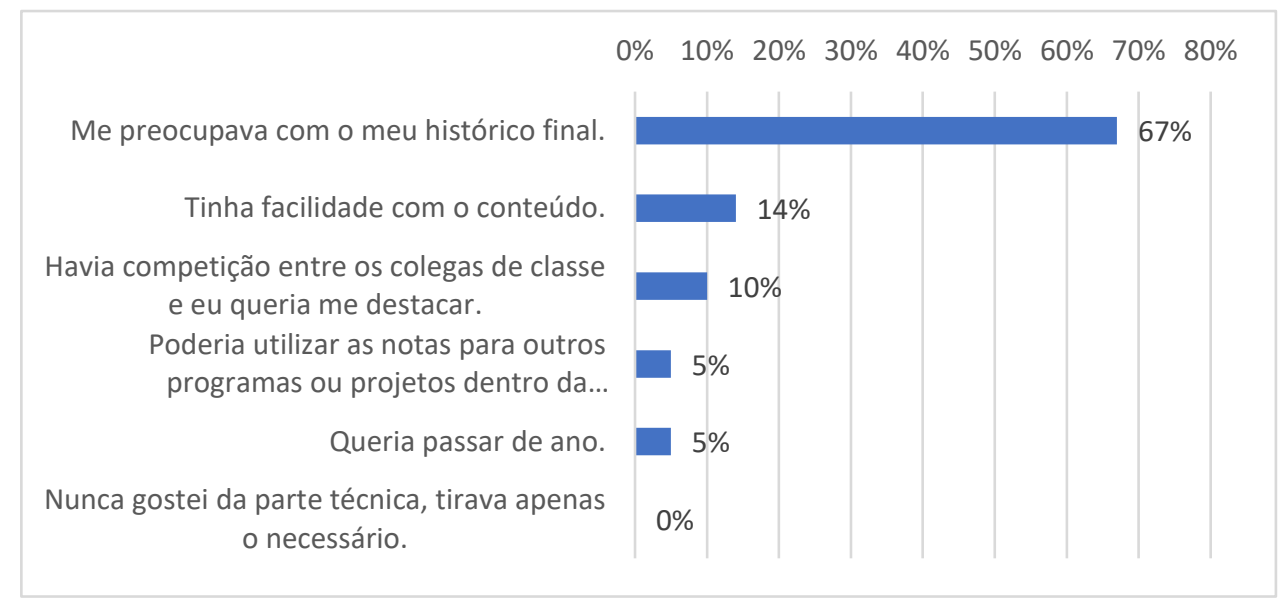

Figura 6. Resultado sobre a questão "Notamos que as notas do Ensino Médio das disciplinas técnicas foram tão boas como das áreas do propedêutico (biologia, sociologia, química, etc). Selecione o principal motivo de você se esforçar em tirar boas notas na parte técnica:"

Em relação a pergunta sobre a continuidade dos seus estudos ("Você seguiu seus estudos (mais cursos ou uma faculdade) após o curso técnico?”), 76\% das estudantes (16 estudantes) afirmaram que ingressaram em outros cursos.

Em relação a área cursada ou em curso na faculdade para o perfil de egresso, a maioria das estudantes cursam/cursam ciências da natureza ( 7 estudantes, ou seja, 44\%), seguida pela área de exatas (5 estudantes, ou seja, 31\%) e depois ciências humanas (4 estudantes, ou seja, 25\%) (Figura 7). Dos cursos citados pelas estudantes na área de exatas temos curso como Análise e Desenvolvimento de Sistemas, Engenharia da Computação, Ciência da Computação, Engenharia de Controle e Automação, Engenharia Elétrica e Licenciatura em Matemática.

Quando as estudantes foram questionadas sobre o que ajudou a realização do curso técnico, a maioria (14 estudantes, ou seja, 88\%) respondeu que isso fez com que descobrissem se gostavam da área ou não. A Figura 8 apresenta as respostas obtidas a esta pergunta.

A hipótese 3 (H3) assume que as disciplinas com maiores notas no Ensino Médio são usadas como referência a área escolhida pelas estudantes ao ingressar no Ensino 
Superior. Considerou-se para essa análise a área de Ciências da Natureza as disciplinas de biologia (BIO), física (FIS) e química (QUI); Ciências Humanas foram consideradas as disciplinas de filosofia (FIL), geografia (GEO), história (HIS) e sociologia (SOC), e, por fim, a área de Ciências Exatas analisou-se separadamente disciplinas de matemática (MAT) e do ensino técnico. As disciplinas do curso técnico são: algoritmo e programação (ALP), organização de computadores e sistemas operacionais (OCS), programação para web I (PWA), rede de computadores (RDC), banco de dados (BDD), análise e projeto de sistemas (APS), linguagem de programação I (LPA), programação para web II (PWB), linguagem de programação II (LPB) e programação para dispositivos móveis (PDM).

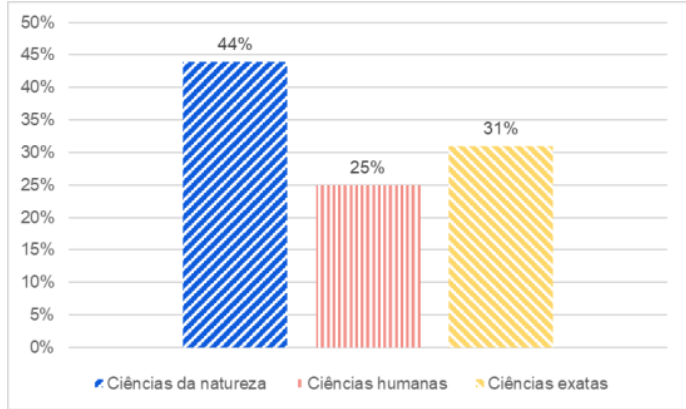

Figura 7. Gráfico com o resultado sobre a questão "Se você continuou seus estudos, qual a área que você está cursando atualmente?"

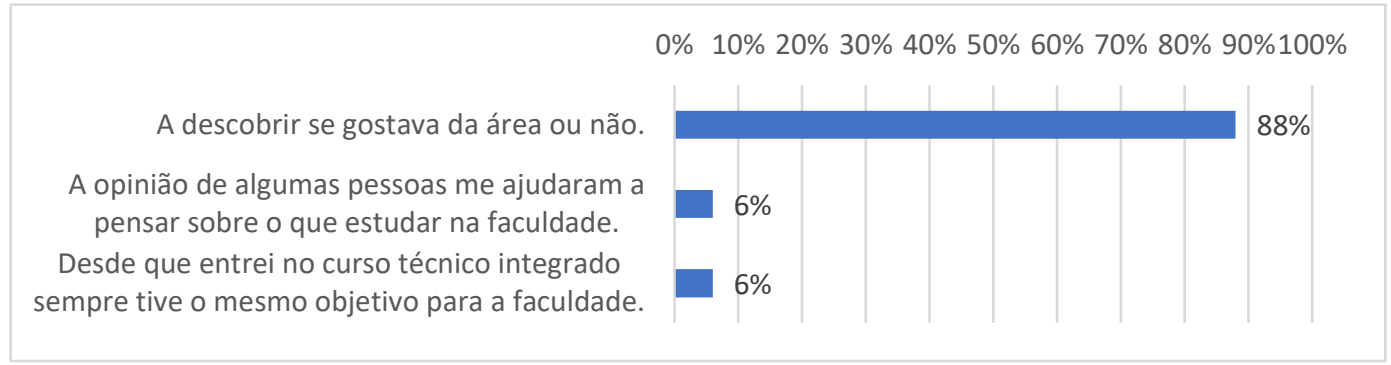

Figura 8. Gráfico com o resultado sobre a questão "Realizar o curso técnico ajudou você:"

A Figura 9 apresenta a média das disciplinas cursadas no $1^{\circ}$ ano do Curso Técnico Integrado ao Ensino Médio por área de conhecimento; na Figura 10 observa-se a média das disciplinas referentes ao $2^{\circ}$ ano cursado; e a Figura 11 mostra as disciplinas do último ano do curso, mostrando novamente a média obtida pelas estudantes.

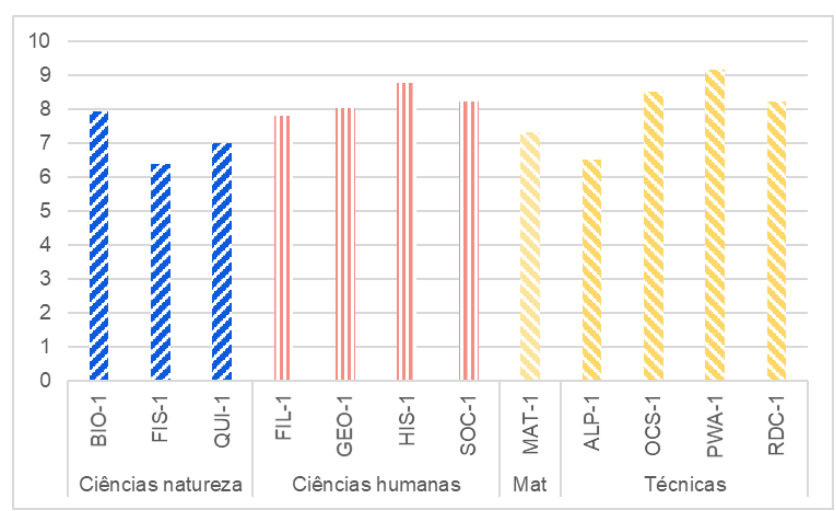

Figura 9. Média das disciplinas relativas ao $1^{\circ}$ ano do curso por áreas de conhecimento 


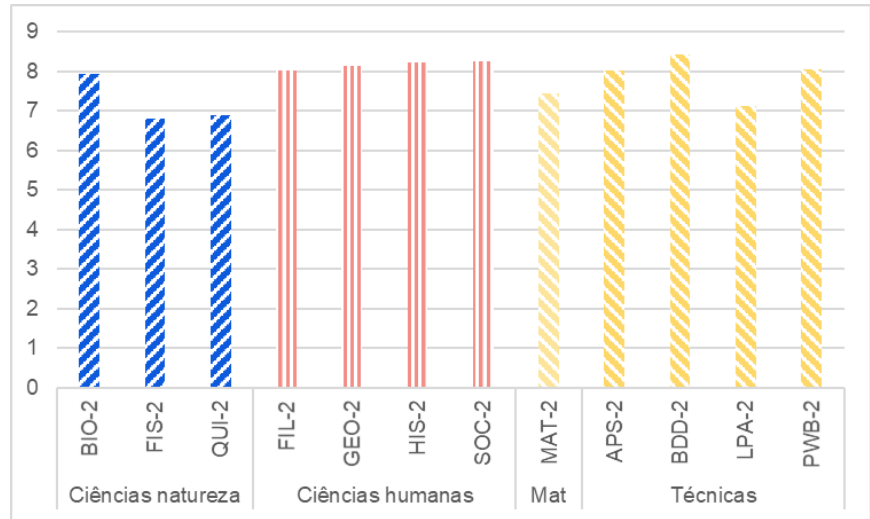

Figura 10. Média das disciplinas relativas ao $2^{\circ}$ ano do curso por áreas de conhecimento

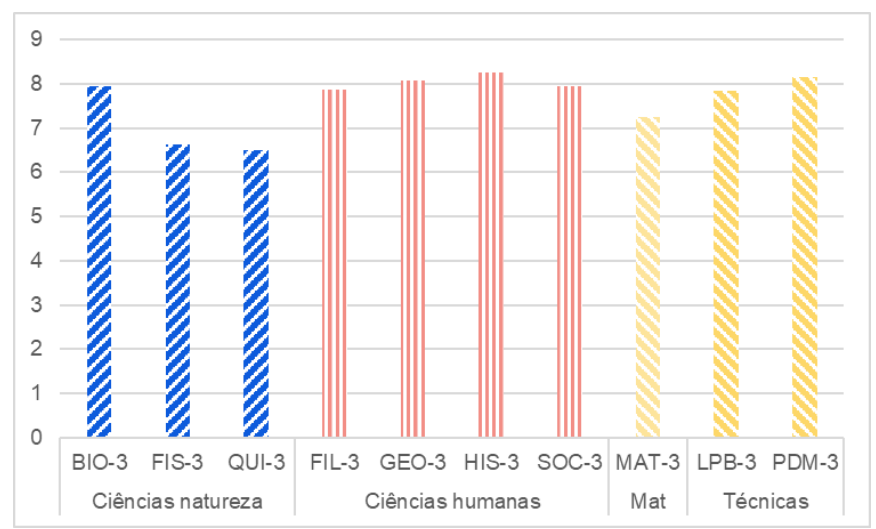

Figura 11. Média das disciplinas relativas ao 30 ano do curso por áreas de conhecimento

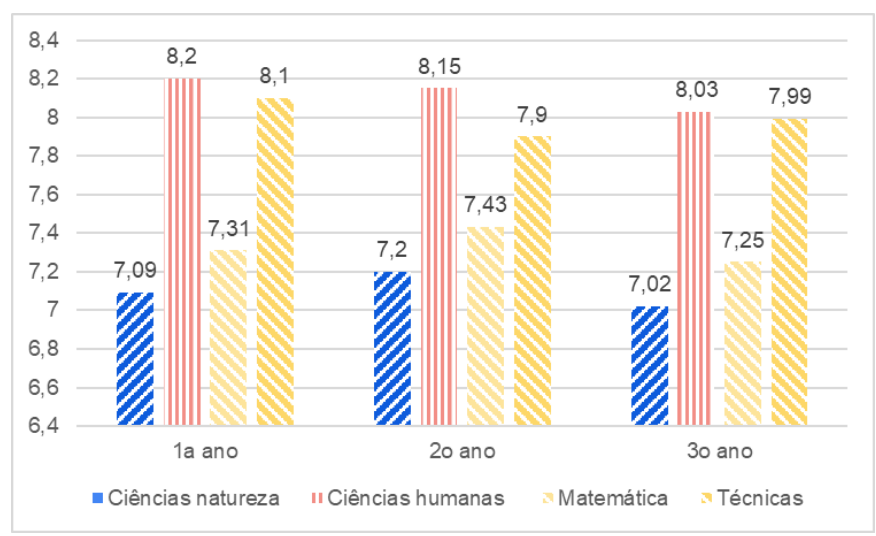

Figura 12. Média por áreas de conhecimento dividido pelo ano de curso

A Figura 12 apresenta a média de cada área considerando as disciplinas identificadas anteriormente, mostrando que as maiores notas são em Ciências Humanas e disciplinas relacionadas ao Ensino Técnico. Pelas Figuras 9, 10 e 11, observa-se que, apesar da maioria das estudantes optarem pelo curso na área de ciências biológicas, as disciplinas associadas a essa área não tem a maior média no curso. 


\section{Conclusões}

A escolha do curso técnico não é uma tarefa fácil a ser tomada na adolescência e tampouco é simples optar pela faculdade a ser realizada. Diversos fatores interferem nesta escolha, tais como a percepção de si, a compreensão da área de interesse, a empregabilidade e fatores socioeconômicos. Ao optar por um curso técnico integrado, os alunos sabem que terão que se dedicar não somente às disciplinas do propedêutico, mas também às disciplinas técnicas.

Pesquisas mostram que há uma diminuição da participação do sexo feminino nas áreas de ciências exatas, no entanto, no curso Técnico em Informática Integrado ao Ensino Médio do IFSP, campus Hortolândia, esse padrão não foi observado. No entanto, apesar de sua maioria feminina, relato anterior identificou que o curso é escolhido pelo método de exclusão em relação a oferta que há no campus ou em sua redondeza, o que nos faz refletir sobre o empenho das estudantes no curso, bem como a aderência das estudantes à área técnica em sua formação após a conclusão do curso técnico.

Este artigo teve como meta levantar as informações em relação ao desempenho das estudantes nas disciplinas técnicas ou não. Tendo como objetivo verificar se apesar do critério adotado para ingresso no curso, as notas nas disciplinas técnicas eram negligenciadas durante o curso.

Os resultados obtidos mostram que as alunas têm uma média de avaliação boa na maioria das disciplinas, as notas com menores médias são as disciplinas de Física (FIS), Algoritmos e Programação (ALP) e Química (QUI). Sendo assim, a H1 mostra que, independentemente da afinidade com o curso, as estudantes tiram notas nas disciplinas técnicas muito semelhantes as notas da formação básica. Para corroborar esse resultado, o questionário aplicado mostra que a maioria se preocupa em ter notas elevadas por causa do histórico escolar.

Considerando a H2 levantada, observa-se uma tendência no universo de egresso onde $31 \%$ das estudantes seguiram na área de exatas. Pesquisa anterior apontava que $28 \%$ das estudantes desejavam continuar seus estudos na área. No entanto não há como concluir se essa hipótese é verdadeira pois seria necessária uma pesquisa com maior número de egressos para verificar em sua totalidade o impacto do curso técnico na escolha do curso superior.

Em relação a $\mathrm{H} 3$, assumindo que a área escolhida para o curso superior está relacionada com a área de melhores notas das estudantes concluiu-se que, nesta pesquisa, essa hipótese não é verdadeira. Apesar de 44\% dos respondentes do sexo feminino optarem por Ciências Biológicas, as notas obtidas na disciplina de Biologia não aparecem entre as melhores notas das estudantes.

Conclui-se com essa pesquisa que as estudantes, apesar de não possuírem um total interesse pela escolha do curso, se preocupam com seu histórico escolar e se esforçam para obtenção de boas notas. Sabe-se que a média das notas depende de diversos aspectos tais como: assimilação de conteúdo da formação anterior, a experiência do professor ao ministrar a aula, diferentes critérios de avaliação, empatia entre alunos e professores, e até mesmo horários de disciplinas em sua grade, visto que a carga horária de um curso técnico integrado faz com que os alunos passem o dia todo em sala de aula, podendo impactar os estudos. 
Essa pesquisa tem interesse em continuar com as coletas de dados para aprimorar o comparativo e evolução das meninas na área de exatas. Uma das considerações feitas pelos estudantes é que não tinham contato com pessoas da área que atuavam no ambiente de trabalho, ações como conversas com mulheres que atuam na área foram aplicadas com o objetivo de melhorar a visão das alunas em relação aos diferentes tipos de empregos possíveis; muitas rejeitam a ideia de programação, mas sabemos que a área de Computação é muito maior que o codificação e precisamos mostrar isso as estudantes.

\section{Referências}

BRASIL (2004). Decreto $n^{\circ} 5.154$, de 23 de julho de 2004. Diário Oficial [da] República do Federativa do Brasil, Poder Executivo, Brasília, DF, 26 jul. 2004. Seção 1, p. 18.

ISACA (2017). Information Systems Audit And Control Association (2017). "The future tech workforce: breaking gender barriers", http:/www.isaca.org/info/2017-women-intechnology-survey/index.html [Online; Acessado em 30 de maio de 2021].

INEP (2019). "Censo da educação superior". https://download.inep.gov.br/educacao_superior/censo_superior/documentos/2020/N otas_Estatisticas_Censo_da_Educacao_Superior_2019.pdf [Online; Acessado em 30 de maio de 2021].

Marques, D. \& Silva, A. C. Uma reflexão sobre a participação das mulheres em cursos de Informática do IFSP câmpus Hortolândia. XI Conference of Latin American Women in Computing (LAWCC). Cidade do Panamá. Setembro. 2019.

Moreira, J., Silva, R., \& Carvalho, M. (2018). Cenários Prospectivos: Uma Visão do Futuro da Presença Feminina em Cursos de Ciência da Computação de uma Instituição de Ensino Superior. Anais do XXVI Workshop sobre Educação em Computação. Porto Alegre: SBC.

Meninas (2021). Meninas Digitais. http://meninas.sbc.org.br/index.php/sobre/ [Online; Acessado em 30 de maio de 2021].

PyLadies (2021). PyLadies Brasil. http://brasil.pyladies.com/about/ [Online; Acessado em 30 de maio de 2021].

Techmakers (2021). Women Techmakers Brasil 2012. http:/gxgbrasil.github.io/wtmbr/ [Online; Acessado em 30 de maio de 2021].

USP (2018). “Por que as mulheres “desapareceram” dos cursos de computação?”. Jormal da USP. https://jornal.usp.br/universidade/por-que-as-mulheres-desapareceram-doscursos-de-computacao/ [Online; Acessado em 30 de maio de 2021].

Women (2021). Women Who Code. In: https://www.womenwhocode.com/ [Online; Acessado em 30 de maio de 2021]. 